\title{
Erratum to: Exploring Factors Affecting Digital Piracy Using the Norm Activation and UTAUT Models: The Role of National Culture
}

\author{
Godwin Udo • Kallol Bagchi • Moutusy Maity
}

Published online: 16 January 2015

(C) Springer Science+Business Media Dordrecht 2015

\section{Erratum to: J Bus Ethics}

DOI 10.1007/s10551-014-2484-1

In the Introduction, paragraph: 4, Line 7, use Udo et al., 2012 instead of Udo et al 2010.

In the reference list add: Udo, G., Bagchi, K., \& Kirs, P.K. (2012). Exploring the role of values on E-service adoption: A comparative analysis of the U.S. and Nigerian users. Computers in Human Behavior, 28(5), 1768-1781. Elsevier, ISSN 0747-5632. (Equal authorship for all authors).

The online version of the original article can be found under doi:10.1007/s10551-014-2484-1.

G. Udo $(\bowtie) \cdot$ K. Bagchi

College of Business Administration, University of Texas at El

Paso, El Paso, USA

e-mail: gudo@utep.edu

K. Bagchi

e-mail: kbagch@utep.edu

M. Maity

Indian Institute of Management Lucknow, Noida Campus,

Noida, India

e-mail: mmaity@iiml.ac.in 